\title{
Hypermobile Disorders and Their Effects on the Hip Joint
}

\author{
Ian M. Clapp ${ }^{1 *}$, Katlynn M. Paul ${ }^{1}$, Edward C. Beck ${ }^{2}$ and Shane J. Nho ${ }^{1}$ \\ ${ }^{1}$ Section of Young Adult Hip Surgery, Division of Sports Medicine, Department of Orthopedic Surgery, Rush University \\ Medical Center, Chicago, IL, United States, ${ }^{2}$ Department of Orthopedic Surgery, Wake Forest Baptist Health, \\ Winston-Salem, NC, United States
}

Hypermobility, or joint hyperlaxity, can result from inherited connective tissue disorders or from micro- or macrotrauma to a joint. The supraphysiologic motion of the hip joint results in capsuloligamentous damage, and these patients have a propensity to develop femoroacetabular impingement syndrome (FAIS) and labral injury. In this review, the recent literature evaluating the definitions, history, incidence, genetics, and histology of hypermobile disorders is investigated. We then review the clinical evaluation, natural history, and resulting instability for patients presenting with a hypermobile hip. Lastly, treatment options and outcomes will be highlighted.

Keywords: hip, femoroacetabular impingement syndrome, hypermobile, hyperlaxity, hypermobility, femoroacetabular impingement

\section{OPEN ACCESS INTRODUCTION}

Edited by: Hypermobility is becoming an increasingly recognized source of pain and instability of the hip

Vassilios S. Nikolaou, National and Kapodistrian University of Athens, Greece

Reviewed by: Narayan Hulse, Fortis Hospital, India James Stoney, St Vincent's Health, Australia

*Correspondence: lan M. Clapp nho.research@rushortho.com

Specialty section: This article was submitted to Orthopedic Surgery, a section of the journal Frontiers in Surgery

Received: 20 August 2020 Accepted: 25 January 2021 Published: 25 March 2021

Citation: Clapp IM, Paul KM, Beck EC and Nho SJ (2021) Hypermobile Disorders and Their Effects on the Hip Joint. Front. Surg. 8:596971. doi: 10.3389/fsurg.2021.596971 joint (1-4). The etiology of hypermobility can range from heritable connective tissue disorders to the result of micro- or macrotrauma to the joint. While hypermobility with or without EhlersDanlos syndrome is relatively rare in the general population, it is of particular interest to hip arthroscopists due to the propensity of these patients to develop femoroacetabular impingement syndrome (FAIS) and labral injury (5). In addition, these patients may be more likely to have capsular laxity following capsular repair resulting in poor outcomes and complications and possibly requiring revision surgery (6-9). Joint hypermobility can be an especially challenging comorbidity and has been associated with a variety of syndromes that exist on a varying spectrum including hip dysplasia, generalized joint hypermobility (GJH), hypermobile Ehlers-Danlos syndrome (hEDS), and hypermobility spectrum disorder. The purpose of this article is to review the causes of hypermobility, the diagnosis, and to summarize literature on hip hypermobility focusing on surgical treatment options and outcomes for these patients.

\section{DEFINITIONS}

Hypermobility, also termed ligamentous laxity, refers to excessive motion of a joint. This can be seen as supraphysiologic motion and often presents without symptoms (3). The hip joint capsule acts as a static stabilizer and is comprised of four ligaments: the iliofemoral, pubofemoral, ischiofemoral, and zona orbicularis. In the native hip, laxity of these ligaments can result in pain and microinstability of the joint (2). However, it must be noted that a joint may be hypermobile yet stable, and the differentiating factor between hypermobility and instability is the presence of symptoms (9). When a majority of an individual's synovial joints are capable of excessive motion, the patient is diagnosed with generalized joint hypermobility (GJH) (10), which is a hallmark of hereditary disorders of connective tissue. 
The Ehlers-Danlos syndromes (EDSs) are a group of heritable connective tissue disorders characterized by abnormal collagen synthesis, which can affect skin, ligaments, blood vessels, and other organs, often causing articular hypermobility (11, 12). Hypermobile EDS (hEDS) is the most common subtype, often resulting in chronic joint pain and frequent dislocations due to joint hyperlaxity, which can negatively affect a patient's quality of life $(13,14)$. Prior to 2017 , it had been proposed that asymptomatic joint hypermobility and joint hypermobility syndrome (JHS) lay at opposite sides of the same spectrum of disorders and that JHS and hEDS may be equivalent disorders (15-17). Per the 2017 International Criteria for Ehlers-Danlos syndrome, JHS is now referred to as hypermobility spectrum disorder (18), which has been proposed as joint hypermobility plus one or more of its secondary manifestations but not satisfying the criteria for any EDS variant (16).

\section{HISTORY AND INCIDENCE}

EDS was first studied and classified in the late 1960s, which resulted in the Berlin nosology in 1986 (19). This was the first attempt to categorize and formalize the nomenclature of the different subtypes of the syndrome. Due to newly noticed clinical and molecular variants, a revised classification, the Villefranche nosology, was proposed a decade later and delineated six subtypes (20). The most current nomenclature and classification system came in 2017 with the International Criteria for Ehlers-Danlos syndrome, which changed the naming of joint hypermobility syndrome to hypermobility spectrum disorder (18).

Naal et al. found the prevalence of GJH to be $33 \%$ in a cohort of 55 patients with FAIS (21) compared to $3 \%$ in normal adult population (22-24). The prevalence of joint hypermobility in the general population is quite low; however, the combined incidence of hypermobility spectrum disorder and hEDS is thought to be 10 in $5,000(25,26)$. GJH is more prevalent in children and adolescence, but this may be attributed to decreases in ranges of motion as age increases (27). It also affects women, Asians, and West Africans more frequently $(28,29)$.

\section{GENETICS AND HISTOLOGICAL FINDINGS}

There is a lack of a well-defined biologic marker for GJH and hypermobility spectrum disorder. In the case of hEDS, an autosomal dominant inheritance pattern with variable penetrance has been elucidated (17). Monozygotic twins have been shown to have higher concordance rates of joint hypermobility compared to dizygotic twins (60 vs. 36\%), suggesting a strong genetic trait that is most likely multifactorial and heterogenous $(30,31)$. Recently, new genes coding for LZTS1 (32) and Tenascin X protein-a protein that plays an important role in organizing and maintaining the structure of connective tissues $(33,34)$-were associated with the hEDS phenotype. However, the exact physiological process remains unknown, and heterozygous TNXB deficiency accounts for a small percentage of hEDS. A genetic mutation seen in a family with hEDS suggests there is overlap with the mutation caused by COL34A, which is normally observed in vascular EDS. This results in intracellular retention of type III collagen (35).

While it has been previously shown that collagen fibril structures are abnormal in patients with hEDS, the etiology is not exactly known (11). The weakened collagen fibers affect the elastic fibers of the skin and the longevity and integrity of ligaments, causing the clinical symptom of hypermobility $(36,37)$.

\section{CLINICAL EVALUATION AND CRITERIA FOR DIAGNOSIS}

Evaluation of hip hypermobility should follow the typical sequence of history, physical exam, and imaging workup. Patients presenting with ligamentous laxity may describe mechanical symptoms or apprehension in certain positions $(3,38)$. A thorough assessment of any prior hip surgery with operative data should be performed, as capsular insufficiency is a leading indication for revision hip arthroscopy (7). Due to the hereditary causes of hypermobility, a detailed family and medical history should be taken. Patients with hEDS often have a history of joint dislocations and extra-articular manifestations such as widespread pain and skin hyperlaxity $(39,40)$. A thorough physical exam is critical in these patients and should include assessment of the Beighton criteria, posterior impingement with extension, the hip dial test, and the axial distraction test (3, 41).

The Beighton score is used to assess GJH and can help distinguish normal laxity from hypermobility (20). It is a ninepoint objective scale, and a patient scoring $>4$ indicates the presence of hypermobility (42-45). The maneuvers performed and scoring are located in Table 1. For diagnosis of hypermobility spectrum disorder and hEDS, the Brighton criteria are used. In order to meet the diagnosis, patients must meet the criteria listed in Table $2(29,46)$. Hakim and Grahame (47) developed a validated five-point questionnaire with a sensitivity of $84 \%$ and specificity of $85 \%$. Individuals answering yes to two or more of these questions suggests hypermobility: "Can you now (or could you ever) place hands flat on floor without bending knees?", "Can you now (or could you ever) bend your thumb to touch your forearm?", “As a child, did you amuse your friends by contorting your body into strange shapes or could you do the splits?", "As a child or teenager, did your kneecap or shoulder dislocate on more than one occasion?", and "Do you consider yourself 'double-jointed'?".

The imaging workup of these patients should include standard hip radiographs [anteroposterior pelvis (AP), false profile view, and Dunn lateral] as well as the splits radiograph. The splits radiograph consistently shows lateral femoral head translation and creation of a vacuum sign (9). The AP film should be examined for the femoral head cliff sign (48), which has been associated with an intraoperative diagnosis of microinstability. 
TABLE 1 | Beighton score for hypermobility.

\begin{tabular}{lll}
\hline Maneuver & Scoring & Example \\
\hline $\begin{array}{l}\text { Passive dorsiflexion of } \\
\text { the fifth finger }>90\end{array}$ & $\begin{array}{l}\text { 1 point for each } \\
\text { side (Maximum } \\
\text { degrees with forearm }\end{array}$ & Score of 2) \\
flat &
\end{tabular}

$\begin{array}{ll}\text { Passive apposition of } & \text { 1 point for each } \\ \text { the thumb to the flexor } & \text { side (Maximum } \\ \text { aspect of the forearm } & \text { Score of 2) }\end{array}$

aspect of the forearm

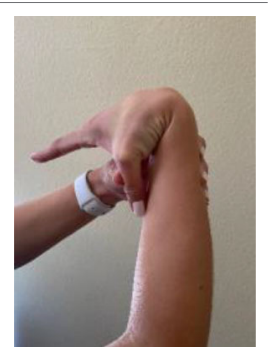

\begin{tabular}{ll}
\hline Hyperextension of & 1 point for each \\
elbow $>10$ degrees & side (Maximum \\
Score of 2)
\end{tabular}

Hyperextensibility of the knee $>10$ degrees

\begin{abstract}
1 point for each side (Maximum Score of 2)
\end{abstract}

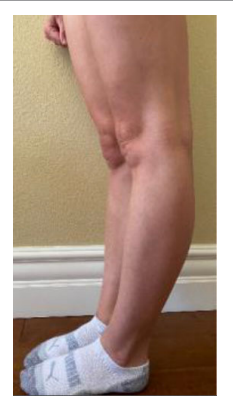
palms on the floor (and with the knees fully extended)
1 point (Maximum Score of 1)

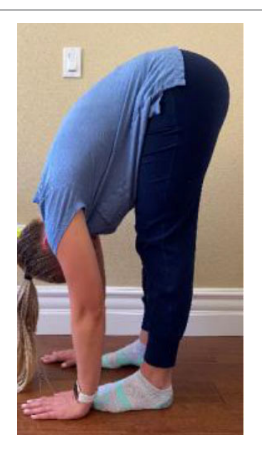

of 9
TABLE 2 | Brighton criteria.

\begin{tabular}{ll}
\hline Major criteria & Description \\
Beighton score $>4$ & $>3$ months in four or more joints \\
Polyarthralgias & \\
Minor criteria & \\
Beighton score $<4$ & $1-3$ if younger than 50-years old, 0-3 if \\
Older than 50-years \\
Arthralgia $>3$ months in 1-3 joints or back \\
pain, spondylolisthesis, spondylolysis, or \\
spondylosis \\
More than one joint, more than one \\
occasion \\
Dislocation or subluxation & tenosynovitis, bursitis) \\
Soft tissue lesions & Arachnodactyly, ratio of arm span to \\
height $>1.03$, ratio of upper segment to \\
lower segment $<0.89$ \\
Harfanoid habitus & Hyperextensibility, striae, thin skin, \\
abnormal scarring \\
Eye signs
\end{tabular}

Varicose veins, hernia, or

uterine/rectal prolapse

Mitral valve prolapse

Exclusions

Presence of Marfan syndrome

Presence of EDS

Other than hEDS

Hypermobility is suggested in the presence of two major criteria, one major and two minor criteria, four minor criteria, or an unequivocally affected first-degree relative in the family. EDS, Ehlers-Danlos syndrome. hEDS, hypermobile Ehlers-Danlos syndrome.

\section{NATURAL HISTORY AND INSTABILITY OF HIP HYPERMOBILITY}

Whether hypermobility is acquired or inherited, it presents with capsuloligamentous laxity and can lead to instability and possibly recurrent subluxations and repeated dislocations of the hip joint $(5,50)$. Acquired hypermobility may result from local micro- or macrotrauma (frank dislocation or injury). Repetitive movements in extreme ranges of motion may cause compensatory soft tissue laxity, which may be desired in some athletes (51). Untreated, these patients may develop recurrent soft tissue injuries and chronic pain, and hypermobile patients may be more prone to developing premature arthritis and capsular degeneration $(15,52,53)$.

Hypermobility may confer a competitive advantage in athletes participating in dance, gymnastics, or cheer where flexibility and extreme ranges of motion are necessary to compete at high levels $(1,5,54)$. However, these biomechanics and repetitive loading can do damage to the cartilage and result in instability of the joint (55). Those with hypermobility are at an increased risk for injury and suffer a longer recovery time $(5,56)$. Furthermore, placing the hip at extreme, supraphysiologic ranges of motion is thought to predispose these patients to developing impingement (5). Extreme ranges of motion can place the hip in a potentially impinging or unstable positions and make the joint 
more susceptible to impingement-induced instability in which the anterior cam impingement creates a fulcrum, resulting in posterolateral instability of the femoral head (57). Charbonnier et al. revealed that significant subluxation of the femoral head was present at extremes of motion and directly correlated with impingement when using MRI in ballet dancers (58). This finding was further supported by Wassilew et al., who found high rates of posterior subluxation in positions of impingement (59). These findings suggest that hypermobility in the presence of FAIS can be a predisposing factor for hip instability.

Hip microinstability is a relatively new concept characterized by hip hypermobility in the setting of hip pain or dysfunction $(60,61)$ and is difficult to diagnose, with no objective criteria for diagnosis (62). Numerous etiologies have been described, and microtrauma in the setting of osseous and soft tissue abnormalities may contribute to the development $(3,62)$. As prior studies have identified the hip capsule as a major stabilizing structure, ligamentous laxity is also a contributing factor to microinstability (63). In a cadaveric study, hip capsular laxity caused increased joint rotations, femoral head translations, and abnormal movement of the femoral head, leading to microinstability (2). This excess motion of the femur relative the acetabulum can lead to damage to the labrum, cartilage, and capsular structures over time (10). Additionally, Devitt et al. demonstrated that in patients undergoing hip arthroscopy for the treatment of FAIS, the presence of GJH was predictive of hip capsular thickness, with those with GJH having a thinner hip capsule $(<10 \mathrm{~mm})$ than those without (64).

\section{TREATMENT AND OUTCOMES}

Management of hypermobility includes both operative and non-operative treatment. Patients with hypermobility disorders should implement lifestyle changes as well as enroll in an exercise program (29). Physical therapy programs should be individualized to consider the patients' condition and focus on strengthening the dynamic musculature surrounding the hip in order to increase stability $(62,65)$.

For hypermobile patients with refractory symptoms of pain or instability, open or arthroscopic surgery may be indicated. Surgical treatment options are directed toward correcting the underlying pathologic etiology such as FAIS or a labral tear, with proper capsular management being integral to successful outcomes and prevention of postoperative instability in these patients $(3,66)$. Capsular closure is necessary, with capsular plication or capsular shift often being used for patients with connective tissue disease and hypermobility $(6,67,68)$. In a cadaveric study performed by Waterman et al. (69), the intracapsular volume of a native hip joint, capsular plication of T-capsulotomy, and capsular shift of the interporal capsulotomy were compared. The authors demonstrated significant reduction in intra-articular volume of the hip undergoing capsular plication of the T-capsulotomy and capsular shift of the interporal capsulotomy when compared to the native hip. Furthermore, in cases of extreme ligamentous insufficiency, capsular reconstruction may be utilized using an iliofemoral ligament reconstruction with an Achilles tendon allograft (70).

Biomechanical studies have demonstrated that capsulotomy size inversely affects the force required for hip distraction and increases hip movement, leading to instability $(71,72)$. Additionally, capsular defects have been reported following capsulotomy during hip arthroscopy, with capsular insufficiency being a leading indication for revision hip arthroscopy (7). In a systematic review, ligamentous laxity was cited as a possible risk factor for post-arthroscopy dislocation, as it was cited in $11.1 \%$ of cases of dislocation (8). Given the inclination of patients with GJH, hypermobility disorder spectrum, and hEDS to have capsular laxity, capsular management is essential for these patients in order to restore sufficient stability.

There is a paucity of literature on surgical outcomes of hypermobile patients. However, available studies demonstrate improvement in patient-reported outcomes and favorable results. Kalisvaart and Safran examined 32 patients with hip instability treated with capsular plication and found significant improvements in the modified Harris Hip Score (mHHS) and the International Hip Outcome Tool (iHOT) score at a minimum of 12 months postoperatively (73). They also demonstrated a high level of return to sport, with 9 out of 11 collegiate or professional athletes returning. Arthroscopic hip surgery has been shown to be effective at treating soft tissue hip instability caused by hEDS. In 16 hips with hEDS, Larson et al. reported significant improvements for the mHHS, 12-Item Short Form Health Survey (SF-12), and VAS pain score at a mean of 45 months (6). This cohort underwent meticulous capsular plication and did not suffer any iatrogenic dislocations postoperatively.

Stone et al. compared outcomes of female patients with and without GJH and demonstrated no significant difference between the groups in terms of postoperative range of motion, pain, and functional outcomes at 2-year follow-up (74). Ukwuani et al. examined return to sport in dancers following hip arthroscopy, with $33 \%$ of the patient cohort meeting the diagnosis of GJH (43). It was shown that hypermobility did not affect 2-year postoperative functional outcome scores or return to dancing activity. These encouraging results are supported by two recent studies. Maldonado et al. performed a matched cohort analysis and exhibited that patients with ligamentous laxity had no significant difference in mHHS, Non-arthritic Hip Score, Hip Outcome ScoreSports Specific Scale, and VAS pain at 2-year follow-up (67). Moreover, these patients achieved minimal clinically important difference and patient acceptable symptomatic state at rates comparable to patients without hypermobility. In a cohort of 63 competitive dancers, there was significant improvement in mHHS and Hip disability and Osteoarthritis Outcome Scores at 3 -years postoperatively, with $84 \%$ of dancers returning to sport (4).

These outcomes support that hip arthroscopy with correct capsular management is a highly effective treatment for patients with hip pathology with concurrent hypermobility. While the short- to mid-term follow-up support improved outcomes, larger studies with long-term outcomes are needed. 


\section{CONCLUSIONS}

Hypermobility refers to the excessive range of motion of a joint and can result from hereditary connective tissue disorders or repetitive local trauma. Regardless of the etiology, hip capsular laxity can lead to instability, pain, and dysfunction, often requiring treatment. Hip arthroscopy with proper capsular management such as capsular plication or shift is an effective treatment for stabilization and produces favorable outcomes in

\section{REFERENCES}

1. Steinberg N, Hershkovitz I, Zeev A, Rothschild B, Siev-Ner I. Joint hypermobility and joint range of motion in young dancers. J Clin Rheumatol. (2016) 22:171-8. doi: 10.1097/RHU.0000000000000420

2. Han S, Alexander JW, Thomas VS, Choi J, Harris JD, Doherty DB, et al. Does capsular laxity lead to microinstability of the native hip? Am J Sports Med. (2018) 46:1315-23. doi: 10.1177/0363546518755717

3. Harris JD. Hypermobile hip syndrome. Oper Tech Sports Med. (2019) 27:10818. doi: 10.1053/j.otsm.2019.04.002

4. Larson CM, Ross JR, Giveans MR, McGaver RS, Weed KN, Bedi A. The Dancer's hip: the hyperflexible athlete: anatomy and mean 3-year arthroscopic clinical outcomes. Arthroscopy. (2020) 36:725-31. doi: 10.1016/j.arthro.2019.09.023

5. Weber AE, Bedi A, Tibor LM, Zaltz I, Larson CM. The hyperflexible hip: managing hip pain in the dancer and gymnast. Sports Health. (2015) 7:34658. doi: 10.1177/1941738114532431

6. Larson CM, Stone RM, Grossi EF, Giveans MR, Cornelsen GD. EhlersDanlos Syndrome: arthroscopic management for extreme soft-tissue hip instability. Arthroscopy. (2015) 31:2287-94. doi: 10.1016/j.arthro.201 5.06 .005

7. Cvetanovich GL, Harris JD, Erickson BJ, Bach BR, Jr., BushJoseph CA, et al. Revision hip arthroscopy: a systematic review of diagnoses, operative findings, and outcomes. Arthroscopy. (2015) 31:1382-90. doi: 10.1016/j.arthro.2014.12.027

8. Yeung M, Memon M, Simunovic N, Belzile E, Philippon MJ, Ayeni OR. Gross instability after hip arthroscopy: an analysis of case reports evaluating surgical and patient factors. Arthroscopy. (2016) 32:1196204.e1. doi: 10.1016/j.arthro.2016.01.011

9. Harris JD, Gerrie BJ, Lintner DM, Varner KE, McCulloch PC. Microinstability of the hip and the splits radiograph. Orthopedics. (2016) 39:e16975. doi: 10.3928/01477447-20151228-08

10. Sacks HA, Prabhakar P, Wessel LE, Hettler J, Strickland SM, Potter HG, et al. Generalized joint laxity in orthopaedic patients: clinical manifestations, radiographic correlates, and management. J Bone Joint Surg Am. (2019) 101:558-66. doi: 10.2106/JBJS.18.00458

11. Parapia LA, Jackson C. Ehlers-Danlos syndrome-a historical review. $\mathrm{Br} J$ Haematol. (2008) 141:32-5. doi: 10.1111/j.1365-2141.2008.06994.x

12. Tinkle B, Castori M, Berglund B, Cohen H, Grahame R, Kazkaz H, et al. Hypermobile Ehlers-Danlos syndrome (a.k.a. Ehlers-Danlos syndrome type III and Ehlers-Danlos syndrome hypermobility type): clinical description and natural history. Am J Med Genet C Semin Med Genet. (2017) 175:4869. doi: 10.1002/ajmg.c.31538

13. De Paepe A, Malfait F. The Ehlers-Danlos syndrome, a disorder with many faces. Clin Genet. (2012) 82:1-11. doi: 10.1111/j.1399-0004.2012.01858.x

14. Rombaut L, Malfait F, Cools A, De Paepe A, Calders P. Musculoskeletal complaints, physical activity and health-related quality of life among patients with the Ehlers-Danlos syndrome hypermobility type. Disabil Rehabil. (2010) 32:1339-45. doi: 10.3109/09638280903514739

15. Ross J, Grahame R. Joint hypermobility syndrome. BMJ. (2011) 342:c7167. doi: 10.1136/bmj.c7167

16. Castori M, Tinkle B, Levy H, Grahame R, Malfait F, Hakim A. A framework for the classification of joint hypermobility and related conditions. Am J Med Genet C Semin Med Genet. (2017) 175:148-57. doi: 10.1002/ajmg.c.31539 this patient group. Further research is needed to clarify longterm outcomes and treatment modalities to reduce instability in these patients.

\section{AUTHOR CONTRIBUTIONS}

All authors had significant contributions to manuscript preparation and editing.

17. Castori M. Ehlers-Danlos syndrome, hypermobility type: an underdiagnosed hereditary connective tissue disorder with mucocutaneous, articular, and systemic manifestations. ISRN Dermatol. (2012) 2012:751768. doi: 10.5402/2012/751768

18. Bloom L, Byers P, Francomano C, Tinkle B, Malfait F. The international consortium on the Ehlers-Danlos syndromes. Am J Med Genet C Semin Med Genet. (2017) 175:5-7. doi: 10.1002/ajmg.c.31547

19. Beighton P, de Paepe A, Danks D, Finidori G, Gedde-Dahl T, Goodman R, et al. International nosology of heritable disorders of connective tissue, Berlin, 1986. Am J Med Genet. (1988) 29:581-94. doi: 10.1002/ajmg.1320290316

20. Beighton P, De Paepe A, Steinmann B, Tsipouras P, Wenstrup RJ. EhlersDanlos syndromes: revised nosology, Villefranche, 1997. Ehlers-Danlos National Foundation (USA) and Ehlers-Danlos Support Group (UK). Am J Med Genet. (1998) 77:31-7.

21. Naal FD, Hatzung G, Müller A, Impellizzeri F, Leunig M. Validation of a self-reported Beighton score to assess hypermobility in patients with femoroacetabular impingement. Int Orthop. (2014) 38:2245-50. doi: 10.1007/s00264-014-2424-9

22. Pacey V, Nicholson LL, Adams RD, Munn J, Munns CF. Generalized joint hypermobility and risk of lower limb joint injury during sport: a systematic review with meta-analysis. Am J Sports Med. (2010) 38:148797. doi: $10.1177 / 0363546510364838$

23. Mulvey MR, Macfarlane GJ, Beasley M, Symmons DP, Lovell K, Keeley P, et al. Modest association of joint hypermobility with disabling and limiting musculoskeletal pain: results from a large-scale general population-based survey. Arthritis Care Res. (2013) 65:1325-33. doi: 10.1002/acr.21979

24. Grahame R. Hypermobility: an important but often neglected area within rheumatology. Nat Clin Pract Rheumatol. (2008) 4:522-4. doi: 10.1038/ncprheum0907

25. Sobey G. Ehlers-Danlos syndrome - a commonly misunderstood group of conditions. Clin Med. (2014) 14:432-6. doi: 10.7861/clinmedicine.14-4-432

26. Hakim AJ, Sahota A. Joint hypermobility and skin elasticity: the hereditary disorders of connective tissue. Clin Dermatol. (2006) 24:521-33. doi: 10.1016/j.clindermatol.2006.07.013

27. Remvig L, Jensen DV, Ward RC. Epidemiology of general joint hypermobility and basis for the proposed criteria for benign joint hypermobility syndrome: review of the literature. J Rheumatol. (2007) 34:804-9.

28. Reuter PR, Fichthorn KR. Prevalence of generalized joint hypermobility, musculoskeletal injuries, and chronic musculoskeletal pain among American University students. PeerJ. (2019) 7:e7625. doi: 10.7717/peerj.7625

29. Kumar B, Lenert P. Joint hypermobility syndrome: recognizing a commonly overlooked cause of chronic pain. Am J Med. (2017) 130:640-7. doi: 10.1016/j.amjmed.2017.02.013

30. Hakim AJ, Cherkas LF, Grahame R, Spector TD, MacGregor AJ. The genetic epidemiology of joint hypermobility: a population study of female twins. Arthritis Rheum. (2004) 50:2640-4. doi: 10.1002/art.20376

31. De Wandele I, Rombaut L, Malfait F, De Backer T, De Paepe A, Calders P. Clinical heterogeneity in patients with the hypermobility type of Ehlers-Danlos syndrome. Res Dev Disabil. (2013) 34:873-81. doi: 10.1016/j.ridd.2012.11.018

32. Syx D, Symoens S, Steyaert W, De Paepe A, Coucke PJ, Malfait F. Ehlers-Danlos syndrome, hypermobility type, is linked to chromosome 8p22-8p21.1 in an extended Belgian family. Dis Markers. (2015) 2015:828970. doi: $10.1155 / 2015 / 828970$ 
33. Morissette R, Chen W, Perritt AF, Dreiling JL, Arai AE, Sachdev V, et al. Broadening the spectrum of Ehlers Danlos syndrome in patients with congenital adrenal hyperplasia. J Clin Endocrinol Metab. (2015) 100:E114352. doi: 10.1210/jc.2015-2232

34. Kaufman CS, Butler MG. Mutation in TNXB gene causes moderate to severe Ehlers-Danlos syndrome. World J Med Genet. (2016) 6:1721. doi: 10.5496/wjmg.v6.i2.17

35. Narcisi P, Richards AJ, Ferguson SD, Pope FM. A family with Ehlers-Danlos syndrome type III/articular hypermobility syndrome has a glycine 637 to serine substitution in type III collagen. Hum Mol Genet. (1994) 3:161720. doi: $10.1093 / \mathrm{hmg} / 3.9 .1617$

36. Magnusson SP, Julsgaard C, Aagaard P, Zacharie C, Ullman S, Kobayasi T, et al. Viscoelastic properties and flexibility of the human muscle-tendon unit in benign joint hypermobility syndrome. J Rheumatol. (2001) 28:2720-5.

37. Hermanns-Lê T, Piérard GE. Ultrastructural alterations of elastic fibers and other dermal components in Ehlers-Danlos syndrome of the hypermobile type. Am J Dermatopathol. (2007) 29:370-3. doi: 10.1097/DAD.0b013e3180de3ec0

38. Russek LN. Examination and treatment of a patient with hypermobility syndrome. Phys Ther. (2000) 80:386-98. doi: 10.1093/ptj/80.4.386

39. Castori M, Dordoni C, Valiante M, Sperduti I, Ritelli M, Morlino S, et al. Nosology and inheritance pattern(s) of joint hypermobility syndrome and Ehlers-Danlos syndrome, hypermobility type: a study of intrafamilial and interfamilial variability in 23 Italian pedigrees. Am J Med Genet A. (2014) 164a:3010-20. doi: 10.1002/ajmg.a.36805

40. Syx D, De Wandele I, Rombaut L, Malfait F. Hypermobility, the Ehlers-Danlos syndromes and chronic pain. Clin Exp Rheumatol. (2017) 35(Suppl. 107):11622.

41. Czaprowski D, Kedra A, Pawłowska P, Kolwicz-Gańko A, Leszczewska J, Tyrakowski M. The examination of the musculoskeletal system based only on the evaluation of pelvic-hip complex muscle and trunk flexibility may lead to failure to screen children for generalized joint hypermobility. PLoS ONE. (2015) 10:e0121360. doi: 10.1371/journal.pone.0121360

42. Beighton P. Hypermobility scoring. $\mathrm{Br} J$ Rheumatol. (1988) 27:163. doi: 10.1093/rheumatology/27.2.163

43. Ukwuani GC, Waterman BR, Nwachukwu BU, Beck EC, Kunze KN, Harris JD, et al. Return to dance and predictors of outcome after hip arthroscopy for femoroacetabular impingement syndrome. Arthroscopy. (2019) 35:11018.e3. doi: 10.1016/j.arthro.2018.10.121

44. Pontiff M, Ithurburn MP, Ellis T, Cenkus K, Stasi SD. Pre- and postoperative self-reported function and quality of life in women with and without generalized joint laxity undergoing hip arthroscopy for femoroacetabular impingement. Int J Sports Phys Ther. (2016) 11:378-87.

45. Remvig L, Jensen DV, Ward RC. Are diagnostic criteria for general joint hypermobility and benign joint hypermobility syndrome based on reproducible and valid tests? A review of the literature. I Rheumatol. (2007) 34:798-803.

46. Grahame R, Bird HA, Child A. The revised (Brighton 1998) criteria for the diagnosis of benign joint hypermobility syndrome (BJHS). J Rheumatol. (2000) 27:1777-9.

47. Hakim AJ, Grahame R. A simple questionnaire to detect hypermobility: an adjunct to the assessment of patients with diffuse musculoskeletal pain. Int J Clin Pract. (2003) 57:163-6.

48. Packer JD, Cowan JB, Rebolledo BJ, Shibata KR, Riley GM, Finlay $\mathrm{AK}$, et al. The cliff sign: a new radiographic sign of hip instability. Orthop J Sports Med. (2018) 6:2325967118807176. doi: 10.1177/23259671188 07176

49. Wyatt M, Weidner J, Pfluger D, Beck M. The Femoro-Epiphyseal Acetabular Roof (FEAR) index: a new measurement associated with instability in borderline hip dysplasia? Clin Orthop Relat Res. (2017) 475:8619. doi: 10.1007/s11999-016-5137-0

50. Carter C, Wilkinson J. Persistent joint laxity and congenital dislocation of the hip. J Bone Joint Surg Br. (1964) 46:40-5. doi: 10.1302/0301-620X.46B1.40

51. Duthon VB, Charbonnier C, Kolo FC, Magnenat-Thalmann N, Becker CD, Bouvet $\mathrm{C}$, et al. Correlation of clinical and magnetic resonance imaging findings in hips of elite female ballet dancers. Arthroscopy. (2013) 29:4119. doi: 10.1016/j.arthro.2012.10.012
52. Bravo JF, Wolff C. Clinical study of hereditary disorders of connective tissues in a Chilean population: joint hypermobility syndrome and vascular EhlersDanlos syndrome. Arthritis Rheum. (2006) 54:515-23. doi: 10.1002/art.21557

53. Smith TO, Easton V, Bacon H, Jerman E, Armon K, Poland F, et al. The relationship between benign joint hypermobility syndrome and psychological distress: a systematic review and meta-analysis. Rheumatology. (2014) 53:11422. doi: 10.1093/rheumatology/ket317

54. Sands WA, Shultz BB, Newman AP. Women's gymnastics injuries. A 5-year study. Am J Sports Med. (1993) 21:271-6. doi: 10.1177/036354659302100218

55. Kolo FC, Charbonnier C, Pfirrmann CW, Duc SR, Lubbeke A, Duthon $\mathrm{VB}$, et al. Extreme hip motion in professional ballet dancers: dynamic and morphological evaluation based on magnetic resonance imaging. Skeletal Radiol. (2013) 42:689-98. doi: 10.1007/s00256-012-1544-9

56. Konopinski MD, Jones GJ, Johnson MI. The effect of hypermobility on the incidence of injuries in elite-level professional soccer players: a cohort study. Am J Sports Med. (2012) 40:763-9. doi: 10.1177/0363546511430198

57. Malik A, Maheshwari A, Dorr LD. Impingement with total hip replacement. J Bone Joint Surg Am. (2007) 89:1832-42. doi: 10.2106/JBJS.F.01313

58. Charbonnier C, Kolo FC, Duthon VB, Magnenat-Thalmann N, Becker CD, Hoffmeyer $\mathrm{P}$, et al. Assessment of congruence and impingement of the hip joint in professional ballet dancers: a motion capture study. Am J Sports Med. (2011) 39:557-66. doi: 10.1177/0363546510386002

59. Wassilew GI, Janz V, Heller MO, Tohtz S, Rogalla P, Hein P, et al. Real time visualization of femoroacetabular impingement and subluxation using 320-slice computed tomography. J Orthop Res. (2013) 31:27581. doi: $10.1002 /$ jor. 22224

60. Bellabarba C, Sheinkop MB, Kuo KN. Idiopathic hip instability. An unrecognized cause of coxa saltans in the adult. Clin Orthop Relat Res. (1998) 355:261-71.

61. Bolia I, Chahla J, Locks R, Briggs K, Philippon MJ. Microinstability of the hip: a previously unrecognized pathology. Muscles Ligaments Tendons J. (2016) 6:354-60. doi: 10.32098/mltj.03.2016.11

62. Kalisvaart MM, Safran MR. Microinstability of the hip-it does exist: etiology, diagnosis and treatment. J Hip Preserv Surg. (2015) 2:12335. doi: 10.1093/jhps/hnv017

63. Adib N, Davies K, Grahame R, Woo P, Murray KJ. Joint hypermobility syndrome in childhood. A not so benign multisystem disorder? Rheumatology. (2005) 44:744-50. doi: 10.1093/rheumatology/keh557

64. Devitt BM, Smith BN, Stapf R, Tacey M, O’Donnell JM. Generalized joint hypermobility is predictive of hip capsular thickness. Orthop J Sports Med. (2017) 5:2325967117701882. doi: 10.1177/2325967117701882

65. Safran MR. Microinstability of the hip-gaining acceptance. J Am Acad Orthop Surg. (2019) 27:12-22. doi: 10.5435/JAAOS-D-1 7-00664

66. Domb BG, Philippon MJ, Giordano BD. Arthroscopic capsulotomy, capsular repair, and capsular plication of the hip: relation to atraumatic instability. Arthroscopy. (2013) 29:162-73. doi: 10.1016/j.arthro.2012.04.057

67. Maldonado DR, Chen JW, Yelton MJ, Rosinsky PJ, Shapira J, Brayboy C, et al. Achieving successful outcomes of hip arthroscopy in the setting of generalized ligamentous laxity with labral preservation and appropriate capsular management: a propensity matched controlled study. Am J Sports Med. (2020) 48:1625-35. doi: 10.1177/0363546520914604

68. Nho SJ, Beck EC, Kunze KN, Okoroha K, Suppauksorn S. Contemporary management of the hip capsule during arthroscopic hip preservation surgery. Curr Rev Musculoskelet Med. (2019) 12:260-70. doi: 10.1007/s12178-019-09564-4

69. Waterman BR, Chen A, Neal WH, Beck EC, Ukwuani G, Clapp IM, et al. Intra-articular volume reduction with arthroscopic plication for capsular laxity of the hip: a cadaveric comparison of two surgical techniques. Arthroscopy. (2019) 35:471-7. doi: 10.1016/j.arthro.2018.09.023

70. Mei-Dan O, Garabekyan T, McConkey M, Pascual-Garrido C. Arthroscopic anterior capsular reconstruction of the hip for recurrent instability. Arthrosc Tech. (2015) 4:e711-5. doi: 10.1016/j.eats.2015.07.019

71. Khair MM, Grzybowski JS, Kuhns BD, Wuerz TH, Shewman E, Nho SJ. The effect of capsulotomy and capsular repair on hip distraction: a cadaveric investigation. Arthroscopy. (2017) 33:559-65. doi: 10.1016/j.arthro.2016.09.019 
72. Bayne CO, Stanley R, Simon P, Espinoza-Orias A, Salata MJ, Bush-Joseph $\mathrm{CA}$, et al. Effect of capsulotomy on hip stability-a consideration during hip arthroscopy. Am J Orthop. (2014) 43:160-5.

73. Kalisvaart MM, Safran MR. Hip instability treated with arthroscopic capsular plication. Knee Surg Sports Traumatol Arthrosc. (2017) 25:2430. doi: 10.1007/s00167-016-4377-6

74. Stone AV, Mehta N, Beck EC, Waterman BR, Chahla J, Ukwuani G, et al. Comparable patient-reported outcomes in females with or without joint hypermobility after hip arthroscopy and capsular plication for femoroacetabular impingement syndrome. J Hip Preserv Surg. (2019) 6:3340. doi: 10.1093/jhps/hnz004
Conflict of Interest: The authors declare that the research was conducted in the absence of any commercial or financial relationships that could be construed as a potential conflict of interest.

Copyright (c) 2021 Clapp, Paul, Beck and Nho. This is an open-access article distributed under the terms of the Creative Commons Attribution License (CC BY). The use, distribution or reproduction in other forums is permitted, provided the original author(s) and the copyright owner(s) are credited and that the original publication in this journal is cited, in accordance with accepted academic practice. No use, distribution or reproduction is permitted which does not comply with these terms. 